OPEN ACCESS

Edited by:

Girish Kale,

University of Leeds, United Kingdom

Reviewed by:

Mukul Pradhan,

National Institute of Technology

Meghalaya, India

Ramendra Sundar Dey,

Institute of Nano Science and

Technology (INST), India

*Correspondence:

Shiwei Lin

linsw@hainanu.edu.cn

Specialty section: This article was submitted to

Functional Ceramics,

a section of the journal

Frontiers in Materials

Received: 14 May 2019 Accepted: 12 September 2019

Published: 04 October 2019

Citation:

Si H, Zhang $X$ and Lin S (2019) A Simple Flow Injection Sensing System for the Real-Time On-Line

Determination of Chemical Oxygen Demand Based on 3D Au-NPS/TiO Nanotube Arrays. Front. Mater. 6:238.

doi: 10.3389/fmats.2019.00238

\section{A Simple Flow Injection Sensing System for the Real-Time On-Line Determination of Chemical Oxygen Demand Based on 3D Au-NPs/ $/ \mathrm{TiO}_{2}$ Nanotube Arrays}

\author{
Hewei Si ${ }^{1,2}$, Xidong Zhang ${ }^{1,2}$ and Shiwei Lin ${ }^{1,2 *}$ \\ ${ }^{1}$ State Key Laboratory of Marine Resource Utilization in South China Sea, Hainan University, Haikou, China, ${ }^{2}$ School of \\ Materials Science and Engineering, Hainan University, Haikou, China
}

3D bare $\mathrm{TiO}_{2}$ nanotube arrays loaded with $\mathrm{Au}$ nanoparticles (3D Au-NPs/TNTAs) were prepared to effectively enhance the photoelectrocatalytic properties. A simple flow injection sensing system was proposed for the real-time on-line determination of chemical oxygen demand using the 3D Au-NPs/TNTAs electrode. The proposed photoelectrochemical oxidative degradation principle of the sensing system was analyzed and validated by the representative organic compounds with known COD values at a potential bias $1.5 \mathrm{~V}$ under UV illumination. A practical detection limit of the sensing system is $0.18 \mathrm{mg} / \mathrm{L}$ and the linear range is $1.92-3,360 \mathrm{mg} / \mathrm{L}$ under the optimum conditions. In the experimental process, the sensing system exhibits long-term stability and good reproducibility.

Keywords: 3D Au-NPs/TNTAs, photoelectrocatalytic, chemical oxygen demand (COD), flow injection sensing, real-time on-line COD determination

\section{INTRODUCTION}

Chemical oxygen demand (COD) is the oxygen equivalent on degradation of the organic compounds, which is a significant parameter of water quality assessment (Kondo et al., 2014). Even though potassium dichromate oxidation method is widely used, many inherent shortcomings such as time-consuming $(2-4 \mathrm{~h})$ reflux process, highly toxic chemicals, corrosiveness and high cost $\left(\mathrm{Ag}_{2} \mathrm{SO}_{4}\right)$ were existing (Allan Moore et al., 1949; Zhang J. et al., 2009; Zhang S. et al., 2009). Photocatalytic methods can effectively solve these problems, but the resulting electron hole pairs are easy to recombine. Currently, an environmentally friendly and rapid photoelectrochemical COD determination way was considered a more promising approach to surmount the recombination of electron-hole pairs further to improve the degradation efficiency (Qu et al., 2011; Li et al., 2012).

However, the photoelectrocatalytic COD determination method implies a relatively narrow working range and poor reproducibility with a stop-flow operation mode in the quartz cell. Also, the shortcomings of conventional photoelectrochemical method are as follows: one is the complex three-electrode structure, the other is that it's hard to improve sensitivity because of inadequate degradation efficiency of working electrode (Liao et al., 2016). 
$\mathrm{TiO}_{2}$ nanotube arrays (TNTAs) extending on the Ti foil have been used as sensing electrode to detect chemical oxygen demand (COD) in recent years, owning to its intrinsic nanotubular architecture and remarkable properties (Li et al., 2006; Grimes, 2007; Zheng et al., 2008). Ti foil could be entirely transformed into nanotubes but a few micrometers thickness of nanotubes are sufficient for performing efficient photocatalysis. In addition, it is easy to have scattering effects in the liquid (Paulose et al., 2007; Kar and Smith, 2009). It's wasteful for Ti foil since it has relatively much loss of photons (Zhuang et al., 2007; Beranek et al., 2009). However, three-dimensional (3D) TNTAs photoelectrode extending radically on a grid of titanium wires can avoid this wastage and because of absorbing the reflected and/or refracted light (Liao et al., 2012). Furthermore, the 3D TNTAs on Ti mesh possess larger surface area than $\mathrm{TiO}_{2}$ nanotube arrays on the $\mathrm{Ti}$ foil which means higher photocatalytic activity. Nevertheless, $\mathrm{TiO}_{2}$ nanotube arrays show shorter lifetime, poor stability, unsatisfactory photocatalytic activity in real application for COD analysis (Liang et al., 2019). Therefore, it is important to propose a new sensor further to improve the weakness of present $\mathrm{TiO}_{2}$ sensing.

To tackle these problems, we propose a flow injection photoelectrocatalytic COD determination method by combining continuous flow injection thin-cell reactor mode and $\mathrm{Au}$ nanoparticles (Au-NPs) loaded on 3D TNTAs. The influence of annealing temperature and anodizing time on the asprepared bare 3D TNTAs were studied. The as-prepared $3 \mathrm{D} \mathrm{TiO}_{2}$ nanotube arrays were characterized via material characterizations and photoelectrochemical testing, such as FESEM, EDS, XRD, photocurrent-density potential characteristics and chronoamperometry experiments, to investigate their morphology, elements, structure, and photoelectrocatalytic activities. A new COD determination analytical principle was proposed, which was experimentally validated with representative organic compounds. Because of the different adsorption position on the surface of $\mathrm{TiO}_{2}$, glucose, glutamic acid and GGA (glucose: glutamic acid $=1: 1$ ) were chosen as the representative organic compounds (Zhang et al., 2006; Han et al., 2010; Liu et al., 2014). The analytical signal generation of the proposed sensing system was optimized on the important experimental parameters such as supporting electrolyte and applied potential bias.

\section{EXPERIMENTAL SECTION}

\section{Preparation of 3D Au-NPs/TNTAs/Ti}

The working electrode was prepared by following steps. Firstly, titanium mesh (>99\% purity, 50 meshes) was sliced rectangle pieces of $30 \times 70 \mathrm{~mm}$, which were fixed by titanium wire. Above treated titanium meshes were dipped into the mixture solution ( $\mathrm{HF}: \mathrm{HNO}_{3}: \mathrm{H}_{2} \mathrm{O}=1: 4: 5$ in $\mathrm{v} / \mathrm{v}$ ) about $30 \mathrm{~s}$ to polish, then treated with acetone, ethanol and ultrapure water by ultra-sonication in order. Subsequently, dried in air. Secondly, the treated titanium mesh was electrochemical anodization in ethylene glycol electrolyte solution (2 wt $\% \mathrm{H}_{2} \mathrm{O}$ and $0.3 \mathrm{wt} \%$ $\mathrm{NH}_{4} \mathrm{~F}$ ) by two electrode configurations in different anodization time $10,20,30$, and $60 \mathrm{~min}$. With the rate of heating $2^{\circ} \mathrm{C} \mathrm{min}^{-1}$, the obtained samples were calcinated at $350,450,550$, and $650^{\circ} \mathrm{C}$ for $3 \mathrm{~h}$ in muffle furnace, respectively. Among them, the electrode material with the best oxidation ability was selected as the asprepared working electrode. Thirdly, to improve photocatalytic activity and stability of the as-prepared working electrode, Au nanoparticles were deposited on the bare 3D TNTAs by the photo-reduction method. The as-prepared working electrode was dipped into the electrolyte consisted of mixture $\left(\mathrm{HAuCl}_{4}\right.$ $(0.1 \mathrm{~g} / \mathrm{L}): \mathrm{HCHO}=100: 1$ in $\mathrm{v} / \mathrm{v})$ in the quartz cell under UV irradiation for $40 \mathrm{~s}$. Then the electrode was washed with ethanol, deionized water and dried in the air, which then was used as the working electrode. As for the counter electrode, Pt nanoparticles were electrodeposited on the titanium mesh treated above at $-0.3 \mathrm{~V}$ for $3 \mathrm{~min}$ in the mixed solution $\left(\mathrm{H}_{2} \mathrm{PtCl}_{6}(0.2 \mathrm{~g} / \mathrm{L})\right.$ : $\mathrm{HCHO}$ $=100: 1 \mathrm{in} \mathrm{v/v)}$ (Si et al., 2019).

\section{Characterization}

The morphologies and microstructure of the electrode material were studied by scanning electron microscopy (FE-SEM) equipped with an energy-dispersive spectrometer (EDS). Crystal phase of the working electrode was analyzed by X-ray diffraction (XRD, Bruker D8) with $\mathrm{Cu} \mathrm{K} \alpha$ radiation. To choose a 3D TNTAs electrode material with best oxidation ability, linear sweep voltammetry (LSV) was performed in cube quartz reactor $(50$ $\times 50 \times 50 \mathrm{~mm}$ ) at room temperature using saturated $\mathrm{Ag} / \mathrm{AgCl}$ $(\mathrm{KCl})$ reference electrode, platinum foil counter electrode and the as-prepared $3 \mathrm{D} \mathrm{TiO}_{2}$ nanotube arrays working electrode in all the experiments.

\section{Fabrication of Flow Injection Sensing System and Measurement of Their Photoelectrocatalytic Real-Time On-Line COD Sensing Properties}

$\mathrm{Au}$ modified $3 \mathrm{D} \mathrm{TiO}_{2}$ Nanotube Arrays as sensing electrode was used for real-time on-line COD determination in our proposed thin-cell reactor which can be seen from our previous work (Si et al., 2019). The schematic diagram and digital image of the real-time on-line thin-cell reactor was shown in Figure S1. The application potential bias and the recording of response current signal were supplied by the electrochemical workstation (Zahner Zennium, Germany). A 5W UV lamp was used as the UV source in the experiment. A $0.2 \mathrm{mM}$ $\mathrm{Na}_{2} \mathrm{SO}_{4}$ solution was as the supporting electrolyte in the photoelectrochemical measurements.

\section{RESULTS AND DISCUSSION}

\section{Characterization of the Electrode Materials}

The effect of preparation parameters of anodic time and calcination temperature on the saturated photocurrent density of the as-prepared electrodes was obtained in LSV under the UV illumination (Zhang J. et al., 2009). As shown in Table S1, the electrode with anodic oxidation for $10 \mathrm{~min}$ and calcination temperature at $450^{\circ} \mathrm{C}$ possess the highest saturated photocurrent density. Therefore, the electrode which is prepared at $60 \mathrm{~V}$ for anodic time $10 \mathrm{~min}$ and calcination temperature at $450^{\circ} \mathrm{C}$ for 
$3 \mathrm{~h}$ (No. 2 in Table S1) was selected as the as-prepared working electrode in our proposed flow injection sensing system.

Figure 1 shows the surface morphology of the working electrode material where highly-ordered TNTAs are distributed uniformly and aligned vertically on the Ti meshes (Liao et al., 2012). The average inner diameter of the 3D TNTAs is $65 \mathrm{~nm}$ with length of $3 \mathrm{um}$, as depicted in Figures 1B,C. Figure 1D displays Au-NPs loaded on the 3D TNTAs and the EDS spectrum further identify the presence of Au-NPs on the bare $3 \mathrm{D}$ TNTAs where the weight of $\mathrm{Au}$ is $0.48 \%$ (Figure S2). The XPS results show the coexistence of $\mathrm{Ti}, \mathrm{O}$ and $\mathrm{Au}$ elements in the prepared nanocomposite, as shown in Figure S3. From the XPS spectra, Ti $2 \mathrm{p} 1 / 2$ and $\mathrm{Ti} 2 \mathrm{p} 3 / 2$ were obtained at $464 \mathrm{eV}$ and $458 \mathrm{eV}$ while $\mathrm{O} 1 \mathrm{~s}$ was at $530 \mathrm{eV}$, which are all consistent with the literature reports (Luo et al., 2016; Siavash et al., 2017). Furthermore, the existence of $\mathrm{Au}$ in the nanocomposite is confirmed by the $\mathrm{Au} 4 \mathrm{f} 7 / 2$ and $\mathrm{Au} 4 \mathrm{f} 5 / 2$ peaks at 83 and $86.7 \mathrm{eV}$, respectively. The role of $\mathrm{Au}$ in the $\mathrm{Au} / \mathrm{TiO}_{2}$ composite enhances the electrical conductivity and raises the optical conductivity further to improve the photoelectrocatalytic properties (Rudra et al., 2018a,b).

Figure 2 shows the XRD patterns of the 3D TNTAs before, and after calcinated. The diffraction peaks attributed to the formation of anatase $\mathrm{TiO}_{2}$ structure after annealing, which has higher photocatalytic activity (Zhang et al., 2016). There appears rutile when the annealing temperature reaches to $650^{\circ} \mathrm{C}$. Furthermore, the photocurrent response of the samples annealed at different temperatures were measured in comparation to that of $\mathrm{Au}$ nanoparticles modified $\mathrm{TiO}_{2}$ nanotube arrays, as depicted in Figure S4. Among them, the sample annealed at $450^{\circ} \mathrm{C}$ has the optimal photocurrent density. The obtained working electrode possess the higher photocurrent density compared to pure $\mathrm{TiO}_{2}$ nanotube arrays, indicating the existence of Au nanoparticles can improve the sensing property.

\section{The Photoelectrocatalytic Properties of the Sensing System}

Figure 3 shows photocurrent response of the sensing system as a function of time at the repeated on/off cycles with applied

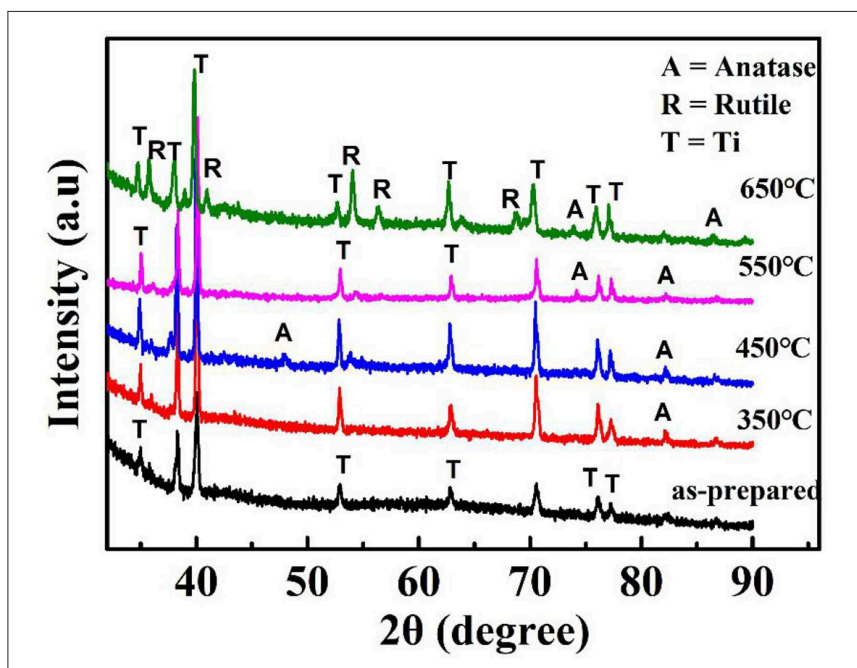

FIGURE 2 |XRD patterns of the reduced at $350,450,550$, and $650^{\circ} \mathrm{C}$, respectively and non-reduced as-prepared 3D TNTAs electrode.
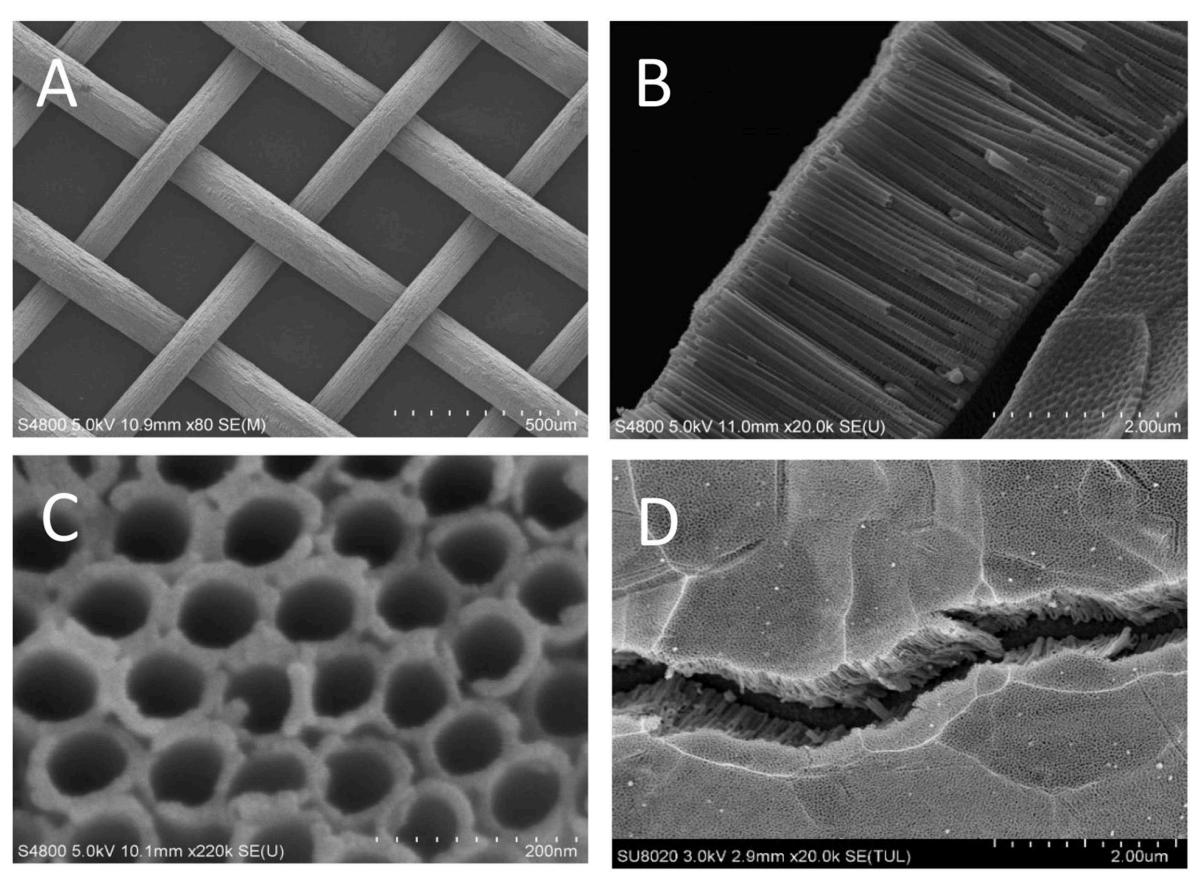

FIGURE 1 | SEM images: (A) Ti meshes, (B) side view and (C) top view of the bare 3D TNTAs, (D) Au-NPs on the bare 3D TNTAs. 


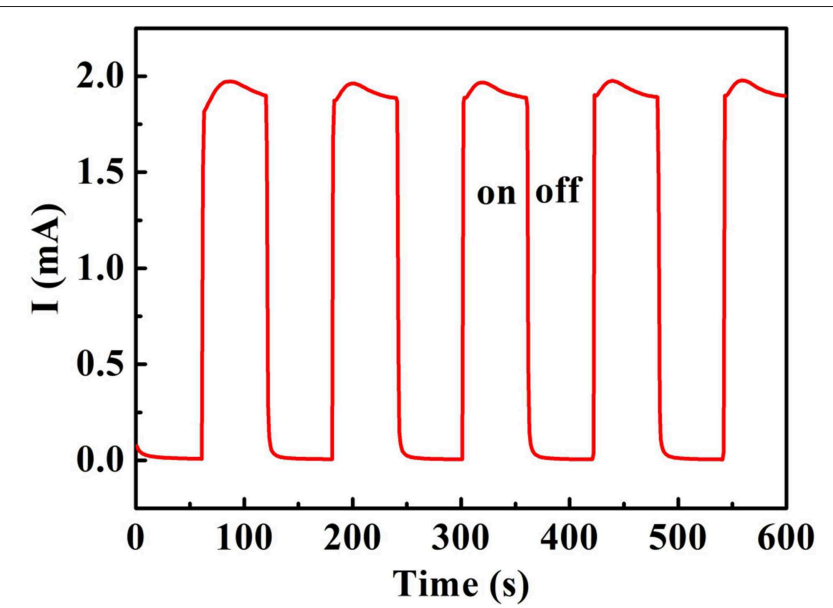

FIGURE 3 | Photocurrent responses of the sensing system as a function of time at the repeated on/off cycles with an applied potential $1.5 \mathrm{~V}$ under UV illumination. $0.2 \mathrm{mM} \mathrm{Na}_{2} \mathrm{SO}_{4}$ solution as the supporting electrolyte.

potential $1.5 \mathrm{~V}$ under $\mathrm{UV}$ illumination. The $0.2 \mathrm{mM} \mathrm{Na} \mathrm{SO}_{4}$ solution is as the supporting electrolyte. The photocurrent density of non-reduced bare 3D TNTAs was measured nearly to be $0 \mathrm{~mA}$ without UV light, but a significant increasing in current value was seen under UV illumination. The non-light current was measured to be low upon switch off the light, but the current quickly increased when turned on the UV light, indicating the sensing system responds quickly to UV source.

Figure 4 shows linear sweep voltammograms of the $\mathrm{Au}$ $\mathrm{NPs} / 3 \mathrm{D}$ TNTAs electrode in $0.2 \mathrm{mM} \mathrm{Na}_{2} \mathrm{SO}_{4}$ and $1 \mathrm{mM}$ glucose in $0.2 \mathrm{mM} \mathrm{Na}_{2} \mathrm{SO}_{4}$ solution with and without $\mathrm{UV}$ irradiation, respectively, in order to investigate the response of oxidation current produced by degradation of organic compounds. As we can see from Figure 4, there was almost no response to oxidation current when glucose was added in the non-UV light (Figure 4A). However, a significant oxidation current appears when ultraviolet light was applied (Figure 4B).

\section{COD Sensing Mechanism}

A new detection principle was proposed based on the postulate that the potential of the counter electrode

$$
\varphi_{\text {counter }}=0
$$

The analog circuit diagram of the proposed COD sensor is as follows Figure 5:

According to the "Closed Circuit Ohm Law," for the proposed COD sensor

$$
E=\mathrm{v}_{\text {reactor }}+I R
$$

Where $E$ is the applied voltage; $v_{\text {reactor }}$ is the voltage on the photoelectrochemical reactor; $I$ is the current in the closed circuit; $R$ is the resistance of the closed circuit except reactor.

When ultraviolet light irradiates the sensing electrode, photoholes possess strong oxidizing capacities which can mineralize organic compounds. Assuming that the organic
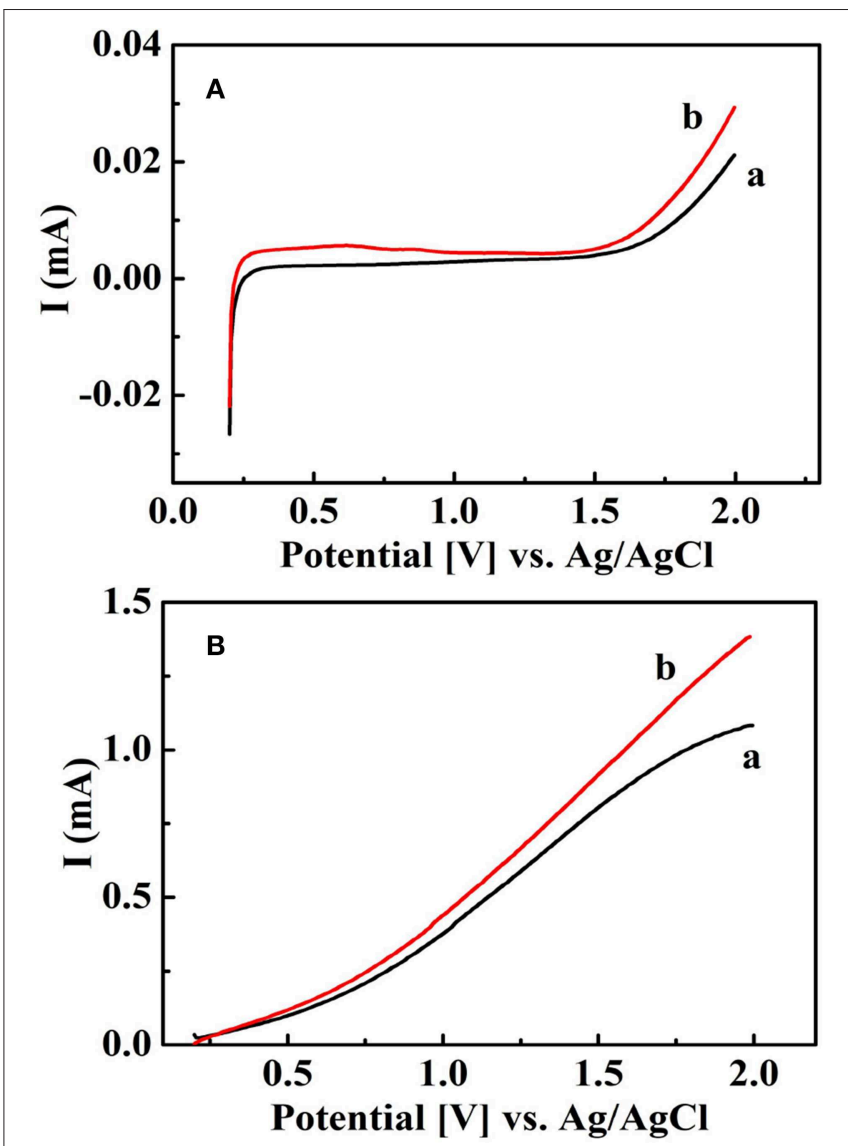

FIGURE 4 | Linear voltammograms of the sensing system: (a) $0.2 \mathrm{mM}$ $\mathrm{Na}_{2} \mathrm{SO}_{4}$ and (b) $0.2 \mathrm{mM} \mathrm{Na}_{2} \mathrm{SO}_{4}$ containing glucose organic using $3 \mathrm{D}$ Au-NPs/TNTAs sensing electrode at the potential scan rate of $10 \mathrm{mVs}^{-1}$ without (A) and with (B) UV illumination.

compounds are stoichiometrically mineralized on surface of the sensing electrode, the potential of sensing electrode can be given by Nernst equation

$$
\varphi_{\text {working }}=-2.30 \frac{k T}{n q} \log C_{m}+A_{1}
$$

Where $C_{m}, T, k, n, A$ are the molar concentration, temperature, Boltzmann constant, the electron transfer number of the individual organic compound and constant, respectively.

Therefore, the applied voltage on the reactor can be given as follows:

$$
v_{\text {reactor }}=-2.30 \frac{k T}{n q} \log C_{m}+A_{1}
$$

According to the relationship between molar concentration $\left(C_{\mathrm{m}}\right)$ and COD concentration [COD] $=8000 n C_{m}$ (Wang et al., 2013), then Equation (4) can be given by:

$$
v_{\text {reactor }}=-2.30 \frac{k T}{n q} \log [C O D]+A_{2}
$$


Figure 6 shows the photocurrent-time profiles with the absence ( $\left.\mathrm{i}_{\text {blank }}\right)$ and existence ( $\left.\mathrm{i}_{\text {total }}\right)$ of organic compounds using the proposed sensing system. When the sensing electrode is illuminated with UV light, iblank obtained in the supporting electrolyte mainly from the oxidation of water, while the observed photocurrent $\left(i_{\text {total }}\right)$ in the sample organic solution originates from both the oxidation of water and the photoelectrocatalytic oxidation of organic compounds. As we know, $i_{\text {net }}$ (net steady state current) originates from $\mathrm{i}_{\text {total }}$ via subtracting the $\mathrm{i}_{\text {blank }}$, which is the step between the blank photocurrent and the total photocurrent in Figure 6 (Chen et al., 2012).

$$
\mathrm{I}_{\text {net }}=\mathrm{i}_{\text {total }}-\mathrm{i}_{\text {blank }}
$$

$\mathrm{I}_{\text {net }}$ can be transformed into the equivalent COD values according to Faraday's law.
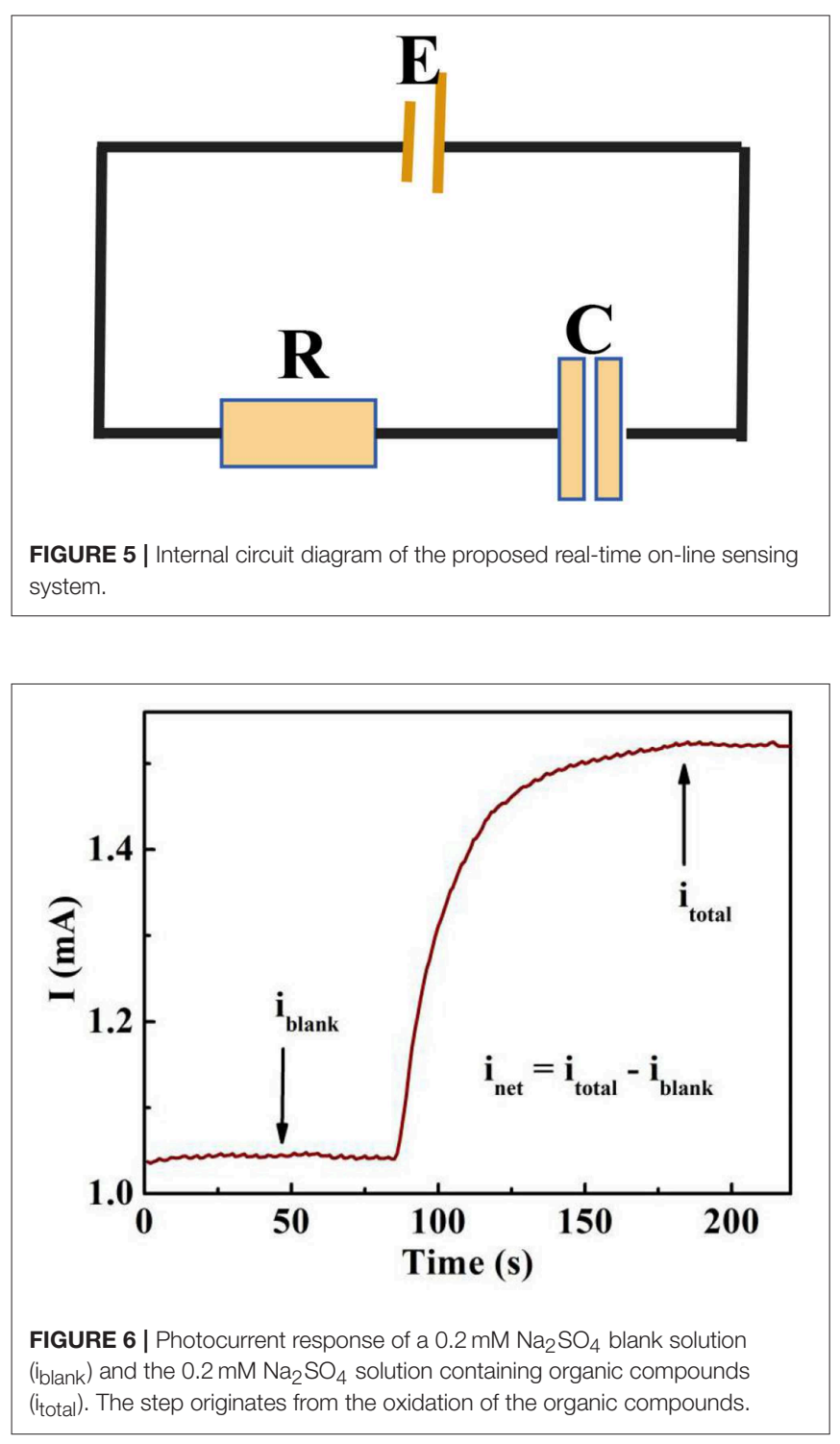

According to Equations (2), (5), and (6), Inet can be given by:

$$
\begin{aligned}
\mathrm{I}_{\text {net }} & =\frac{2.30 \frac{\mathrm{kT}}{\mathrm{nq}} \log [C O D]-A_{1}+v_{\mathrm{blank}}}{R} \\
& =\frac{2.30 \frac{\mathrm{k} T}{\mathrm{nq}} \log [C O D]}{R}+A \\
& =\alpha \log [C O D]+A
\end{aligned}
$$

Where both $\alpha$ and $A$ are constant. The $\mathrm{I}_{\text {net }}$ possess linear relationship with the logarithm of the COD value.

\section{COD Sensing Properties}

Photogenerated hole is a strong oxidant for degradation of organic compounds during the process of photocatalytic oxidation. The combination of photogenerated electrons and holes often limits the degradation efficiency. However, the addition of a bias voltage can transfer photogenerated electrons to the internal circuit, thereby improving the degradation efficiency (Zheng et al., 2008). In order to find the proper applied bias, the effect of applied bias on net current is studied under different bias conditions ( $\mathrm{Li}$ et al., 2014), as shown in Figure 7A. The determined $I_{\text {net }}$ values are lower than that the applied bias value is above $1 \mathrm{~V}$, however, the obtained $\mathrm{I}_{\text {net }}$ values are not fluctuation when the applied voltages are between 1.0 and $1.5 \mathrm{~V}$. In all the experiments, the applied bias $1.5 \mathrm{~V}$ was chosen as the proper voltage. In addition, the current signal is influenced by the large solution resistance due to the solution channel in the thin-layer reactor. The influence of supporting electrolyte concentration on the generated photocurrent is also studied. In Figure $\mathbf{7 B}$, the current rises with the increase of conductive ions at a certain concentration range. The current reaches its saturation value at higher electrolyte concentration. Thus, $0.2 \mathrm{mM} \mathrm{Na}_{2} \mathrm{SO}_{4}$ was selected as the optimal supporting electrolyte concentration.

In order to validate the proposed COD analysis principle, some pure organic compounds such as glucose and sucrose and synthetic sample (GGA) were chosen as the representative organic compounds. Chronoamperometric experiments were performed via injecting various molar concentration organic compounds at a constant applied bias $\mathrm{V}=1.5 \mathrm{~V}$ with $\mathrm{UV}$ light. When various concentration organic compounds were added, the rapidly raising photocurrent responses were obtained and then recorded by the electrochemical workstation (Zahner zennium, Germany). The relationship between $I_{\text {net }}$ and molar concentration of individual organic compounds with equal COD values of each is presented in Figure 8A. In addition, the relationship between $\mathrm{I}_{\text {net }}$ and the equivalent theoretical COD values converted from the molar concentrations of organic compounds $\left([\mathrm{COD}]=8000 \mathrm{nC}_{\mathrm{m}}\right)$ were deduced in Figure 8B. In the figure, $I_{\text {net }}$ possess linear relationship with the logarithm of the organic compound concentrations studied in this paper. The plots display that the investigated organic compounds are fitted into a line $\mathrm{y}=0.000887 \log (\mathrm{x})-3.22 \times 10^{-4}$ (where $\mathrm{y}$ represents $I_{\text {net }}$ obtained from organics oxidation, $x$ represents the COD value of the organics) with $R^{2}=0.975$, indicating the proportional relationship between the $\mathrm{I}_{\text {net }}$ and the COD value 


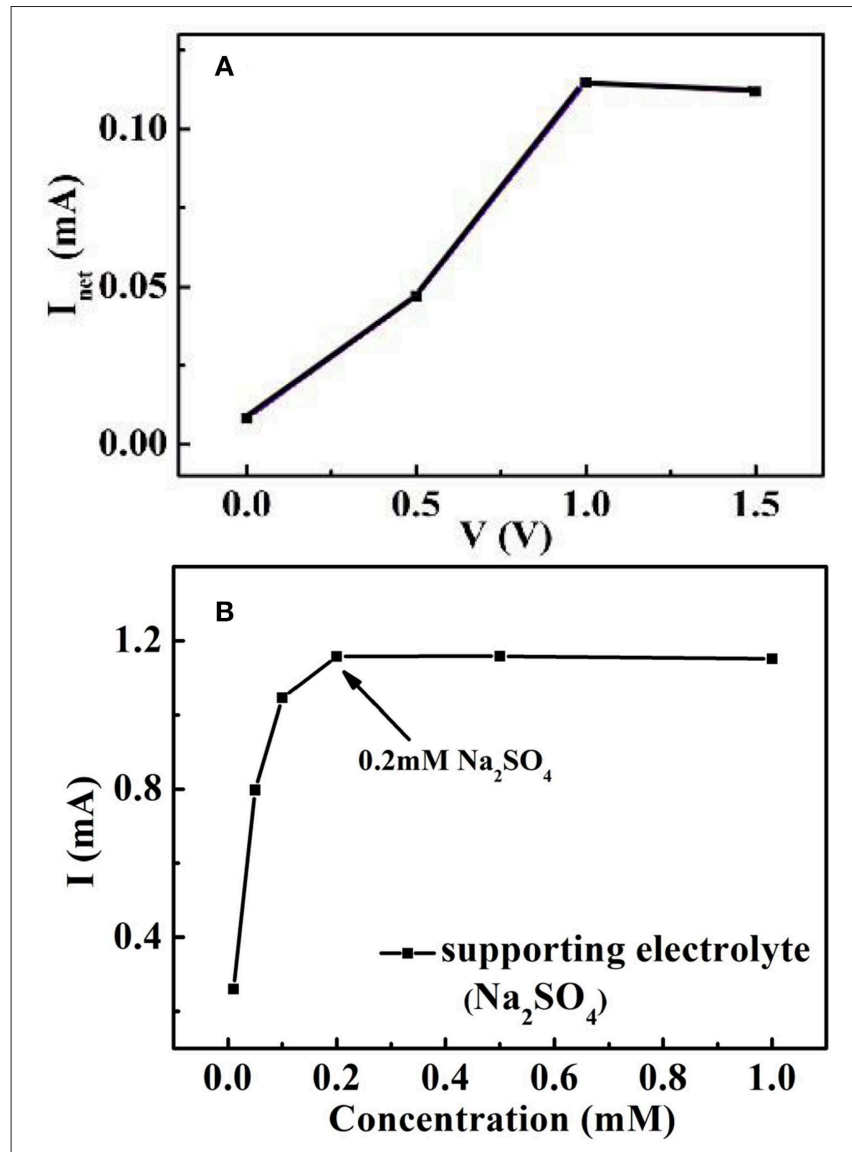

FIGURE 7 | Optimization of the real-time on-line sensing system: effect of (A) applied voltage and (B) supporting electrolyte concentration on photocurrent.

for the 3D Au-NPs/TNTAs COD sensing system. Furthermore, a wide working linear range from 1.92 to $3,360 \mathrm{mg} \mathrm{L}^{-1}$ were obtained. The proposed COD sensing system also possess a detection limit of $0.18 \mathrm{mg} \mathrm{L}^{-1} \mathrm{COD}(\mathrm{S} / \mathrm{N}=3)$.

\section{Reproducibility and Operational Stability of the Proposed Sensing System}

The reproducibility of the photoelectrochemical sensor was assessed by measuring the current signal at $19.2 \mathrm{mg} / \mathrm{L}$ COD (Yao et al., 2015). The relative standard deviation was $2.5 \%$ for 11 determinations, suggesting excellent reproducibility. To study the long-term stability about the proposed sensing system, response photocurrent to $0.1 \mathrm{mM}$ glucose (theoretical COD value $19.2 \mathrm{mg} / \mathrm{L}$ ) was measured during 10 days period. The RSD is $3.7 \%$, showing good stability of the sensing system.

\section{CONCLUSIONS}

A real-time on-line sensing system combining with 3D AuNPs/TNTAs sensing electrode and photoelectrochemical reactor is proposed toward the determination of COD, which is on account of the relationship between the COD values and the quantity captured charge applying the photoelelctrocatalytic

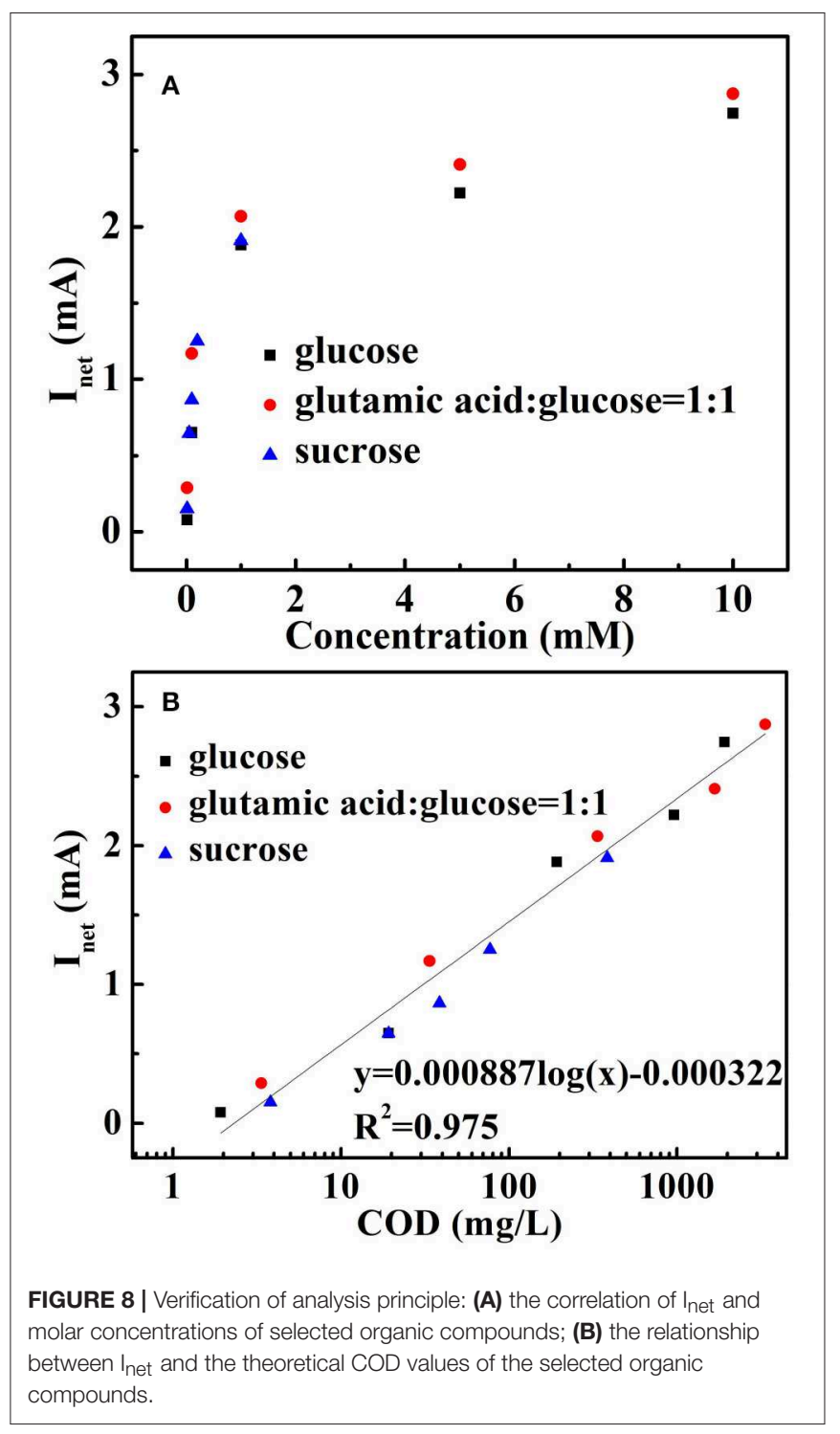

method. In the photoelectrochemical experiments, the optimum conditions such as applied bias and supporting electrolyte were investigated. Glucose, sucrose and GGA were chosen as the representative organic compounds to validated the proposed sensing principle. The sensing photocurrent presents a linear relationship with the logarithm of COD values. The proposed sensing system shows a detection limit of $0.18 \mathrm{mg} / \mathrm{L}$ with the linear range from 1.96 to $3,360 \mathrm{mg} / \mathrm{L}$.

\section{DATA AVAILABILITY STATEMENT}

All datasets generated for this study are included in the manuscript/Supplementary Files.

\section{AUTHOR CONTRIBUTIONS}

HS designed and conducted the experiments and analyzed the results. XZ prepared the bare 3D TNTAs nanotube arrays. SL revised, read, and approved the submitted version. 


\section{FUNDING}

This work was supported by the National Natural Science Foundation of China (Grant No. 61764003), Major Science and Technology Planning Project of Hainan Province (ZDKJ201810).

\section{REFERENCES}

Allan Moore, W., Kroner, R. C., and Ruchhoft, C. C. (1949). Dichromate reflux method for determination of oxygen consumed. Anal. Chem. 21, 953-957. doi: 10.1021/ac60032a020

Beranek, R., Macak, J. M., Gärtner, M., Meyer, K., and Schmuki, P. (2009). Enhanced visible light photocurrent generation at surface-modified $\mathrm{TiO}_{2}$ nanotubes. Electrochim. Acta 54, 2640-2646. doi: 10.1016/j.electacta.2008.10.063

Chen, H., Zhang, J., Chen, Q., Li, J., Li, D., Dong, C., et al. (2012). Assessment of a COD analytical method based on the photoelectrocatalysis of a $\mathrm{TiO}_{2}$ nanotube array sensor. Anal. Methods 4:1790. doi: 10.1039/c2ay05940a

Grimes, C. A. (2007). Synthesis and application of highly ordered arrays of $\mathrm{TiO}_{2}$ nanotubes. J. Mater. Chem. 17, 1451-1457. doi: 10.1039/b701168g

Han, Y., Zhang, S., Zhao, H., Wen, W., Zhang, H., Wang, H., et al. (2010). Photoelectrochemical characterization of a robust $\mathrm{TiO}_{2} / \mathrm{BDD}$ Heterojunction electrode for sensing application in aqueous solutions. Langmuir 26, 6033-6040. doi: 10.1021/la903706e

Kar, A., and Smith, Y. R. (2009). Improved photocatalytic degradation of textile dye using titanium dioxide nanotubes formed over titanium wires. Environ. Sci. Technol. 43, 3260-3265. doi: 10.1021/es8031049

Kondo, T., Tamura, Y., Hoshino, M., Watanabe, T., Aikawa, T., Yuasa, M., et al. (2014). Direct determination of chemical oxygen demand by anodic decomposition of organic compounds at a diamond electrode. Anal. Chem. 86, 8066-8072. doi: 10.1021/ac500919k

Li, J., Zheng, L., Li, L., Shi, G., Xian, Y., and Jin, L. (2006). Photoelectrosynergistic catalysis at $\mathrm{Ti} / \mathrm{TiO}_{2} / \mathrm{PbO}_{2}$ electrode and its application on determination of chemical oxygen demand. Electroanalysis 18, 2251-2256. doi: 10.1002/elan.200603644

Li, L., Zhang, S., Li, G., and Zhao, H. (2012). Determination of chemical oxygen demand of nitrogenous organic compounds in wastewater using synergetic photoelectrocatalytic oxidation effect at $\mathrm{TiO}_{2}$ nanostructured electrode. Anal. Chim. Acta 754, 47-53. doi: 10.1016/j.aca.2012.10.008

Li, X., Bai, J., Liu, Q., Li, J., and Zhou, B. (2014). $\mathrm{WO}_{3} / \mathrm{W}$ nanopores sensor for Chemical Oxygen Demand (COD) determination under visible light. Sensors 14, 10680-10690. doi: 10.3390/s140610680

Liang, L., Yin, J., Bao, J., Cong, L., Huang, W., Lin, H., et al. (2019). Preparation of Au nanoparticles modified $\mathrm{TiO}_{2}$ nanotube array sensor and its application as chemical oxygen demand sensor. Chin. Chem. Lett. 30, 167-170. doi: 10.1016/j.cclet.2018.01.049

Liao, J., Lin, S., Zeng, M., and Yang, Y. (2016). A miniature photoelectrochemical sensor based on organic electrochemical transistor for sensitive determination of chemical oxygen demand in wastewaters. Water Res. 94, 296-304. doi: 10.1016/j.watres.2016.02.061

Liao, J., Lin, S., Zhang, L., Pan, N., Cao, X., and Li, J. (2012). Photocatalytic degradation of methyl orange using a $\mathrm{TiO}_{2} / \mathrm{Ti}$ mesh electrode with 3D nanotube arrays. ACS Appl. Mater. Interfaces 4, 171-177. doi: 10.1021/am201220e

Liu, C., Zhao, H., Ma, Z., An, T., Lau, C., Zhao, L., et al. (2014). Novel environmental analytical system based on combined biodegradation and photoelectrocatalytic detection principles for rapid determination of organic pollutants in wastewaters. Environ. Sci. Technol. 48, 1762-8. doi: $10.1021 /$ es4031358

Luo, J., Chen, J., Wang, H., and Liu, H. (2016). Ligand-exchange assisted preparation of plasmonic $\mathrm{Au} / \mathrm{TiO}_{2}$ nanotube arrays photoanodes for visible-light-driven photoelectrochemical water splitting. J. Power Sources 303, 287-293. doi: 10.1016/j.jpowsour.2015.11.016

Paulose, M., Prakasam, H. E., Varghese, O. K., Peng, L., Popat, K. C., Mor, G. K., et al. (2007). $\mathrm{TiO}_{2}$ nanotube arrays of $1000 \mu \mathrm{m}$ length by anodization of titanium foil: phenol red diffusion. J. Phys. Chem. C 111, 14992-14997. doi: $10.1021 /$ jp075258r

\section{SUPPLEMENTARY MATERIAL}

The Supplementary Material for this article can be found online at: https://www.frontiersin.org/articles/10.3389/fmats. 2019.00238/full\#supplementary-material

Qu, X., Tian, M., Chen, S., Liao, B., and Chen, A. (2011). Determination of chemical oxygen demand based on novel photoelectro-bifunctional electrodes. Electroanalysis 23, 1267-1275. doi: 10.1002/elan.2010 00641

Rudra, S., Nayak, A. K., Chakraborty, R., Maji, P. K., and Pradhan, M. (2018a). Synthesis of $\mathrm{Au}-\mathrm{V}_{2} \mathrm{O}_{5}$ composite nanowires through the shape transformation of a vanadium(iii) metal complex for high-performance solidstate supercapacitors. Inorg. Chem. Front. 5, 1836-1843. doi: 10.1039/C8QI0 $0325 \mathrm{D}$

Rudra, S., Nayak, A. K., Koley, S., Chakraborty, R., Maji, P. K., and Pradhan, M. (2018b). Redox-mediated shape transformation of $\mathrm{Fe}_{3} \mathrm{O}_{4}$ nanoflakes to chemically stable $\mathrm{Au}-\mathrm{Fe}_{2} \mathrm{O}_{3}$ composite nanorods for a high-performance asymmetric solid-state supercapacitor device. ACS Sustain. Chem. Eng. 7, 724-733. doi: 10.1021/acssuschemeng.8b04300

Si, H., Pan, N., Zhang, X., Liao, J., Rumyantseva, M. N., Gaskov, A. M., et al. (2019). A real-time on-line photoelectrochemical sensor toward chemical oxygen demand determination based on field-effect transistor using an extended gate with $3 \mathrm{D} \mathrm{TiO}_{2}$ nanotube arrays. Sens. Actuators B Chem. 289, 106-113. doi: 10.1016/j.snb.2019.03.071

Siavash, R., Kia, G., Goh, L., Dolati, A., and Ghorbani, M. (2017). Applied catalysis B: environmental sunlight-driven photoelectrochemical sensor for direct determination of hexavalent chromium based on $\mathrm{Au}$ decorated rutile $\mathrm{TiO}_{2}$ nanorods. Appl. Catal. B Environ. 201, 411-418. doi: 10.1016/j.apcatb.2016.08.026

Wang, C., Wu, J., Wang, P., Ao, Y., Hou, J., and Qian, J. (2013). Photoelectrocatalytic determination of chemical oxygen demand under visible light using $\mathrm{Cu}_{2} \mathrm{O}$-loaded $\mathrm{TiO}_{2}$ nanotube arrays electrode. Sens. Actua. B Chem. 181, 1-8. doi: 10.1016/j.snb.2013.02.011

Yao, N., Liu, Z., Chen, Y., Zhou, Y., and Xie, B. (2015). A novel thermal sensor for the sensitive measurement of chemical oxygen demand. Sensors 15, 20501-20510. doi: 10.3390/s150820501

Zhang, J., Zhou, B., Zheng, Q., Li, J., Bai, J., Liu, Y., et al. (2009). Photoelectrocatalytic COD determination method using highly ordered $\mathrm{TiO}_{2}$ nanotube array. Water Res. 43, 1986-1992. doi: 10.1016/j.watres.2009.01.035

Zhang, S., Jiang, D., and Zhao, H. (2006). Development of chemical oxygen demand on-line monitoring system based on a photoelectrochemical degradation principle. Environ. Sci. Technol. 40, 2363-2368. doi: 10.1021/es0520181

Zhang, S., Li, L., and Zhao, H. (2009). A portable photoelectrochemical probe for rapid determination of chemical oxygen demand in wastewaters. Environ. Sci. Technol. 43, 7810-7815. doi: 10.1021/es901320a

Zhang, Z., Chang, X., and Chen, A. (2016). Determination of chemical oxygen demand based on photoelectrocatalysis of nanoporous $\mathrm{TiO}_{2}$ electrodes. Sens. Actua. B Chem. 223, 664-670. doi: 10.1016/j.snb.2015.10.001

Zheng, Q., Zhou, B., Bai, J., Li, L., Jin, Z., Zhang, J., et al. (2008). Self-organized $\mathrm{TiO}_{2}$ nanotube array sensor for the determination of chemical oxygen demand. Adv. Mater. 20, 1044-1049. doi: 10.1002/adma.200701619

Zhuang, H. F., Lin, C. J., Lai, Y. K., Sun, L., and Li, J. (2007). Some critical structure factors of titanium oxide nanotube array in its photocatalytic activity. Environ. Sci. Technol. 41, 4735-4740. doi: 10.1021/es0702723

Conflict of Interest: The authors declare that the research was conducted in the absence of any commercial or financial relationships that could be construed as a potential conflict of interest.

Copyright (C) 2019 Si, Zhang and Lin. This is an open-access article distributed under the terms of the Creative Commons Attribution License (CC BY). The use, distribution or reproduction in other forums is permitted, provided the original author(s) and the copyright owner(s) are credited and that the original publication in this journal is cited, in accordance with accepted academic practice. No use, distribution or reproduction is permitted which does not comply with these terms. 